\title{
Efeito de Genótipos de Milho no Desenvolvimento de Spodoptera frugiperda (J.E. Smith)
}

\author{
Luís C. P. Silveira ${ }^{1}$, José D. Vendramim² e Carlos J. Rossetto ${ }^{1}$ \\ ${ }^{1}$ Instituto Agronômico de Campinas, Caixa postal 28, 13001-970, Campinas, SP. \\ ${ }^{2}$ Departamento de Entomologia, ESALQ/USP, Caixa postal 9, 13418-900, Piracicaba, SP. \\ An. Soc. Entomol. Brasil 26(2): 291-298 (1997) \\ Effect of Corn Genotypes on the Development of Spodoptera \\ frugiperda (J.E. Smith)
}

\begin{abstract}
The effect of corn (Zea mays) genotypes on the biology of Spodoptera frugiperda (J.E.Smith) was evaluated to identify possible sources of resistance. The development of the insect was compared on 5 inbred lines from Mississippi (EUA), 5 genotypes from Instituto Agronômico de Campinas and one genotype from Central America (Zapalote Chico). Results showed that the duration of larval stage and larval weight 10 days after emergence were affected by genotypes Mp707, Zapalote Chico, Mp701, Mp706 and Mp705. Viability of larval stage was affected by genotypes Mp705 and Mp706, while the pupal weight was smaller on genotype IAC103 BPl. The duration and viability of pupal stage, sexual ratio, and \% of malformed adults were less important to discriminate these cultivars. It was concluded that the least suitable genotypes for development of the insect were Mp707 and Zapalote Chico, followed by Mp706, Mp705 and Mp701, while the most adequates were IAC103 N, IAC701 $\mathrm{N}$ and Mp496.
\end{abstract}

KEY WORDS: Insecta, fall armyworm, plant resistance, Zea mays.

RESUMO - Estudou-se a biologia de Spodoptera frugiperda (J.E.Smith) em genótipos de milho (Zea mays), comparando-se diferentes fontes de resistência: 5 linhagens provenientes do Mississippi (EUA), 5 genótipos provenientes do Instituto Agronômico de Campinas e uma raça centro-americana (Zapalote Chico). Nos genótipos Mp707, Zapalote Chico, Mp701, Mp706 e Mp705, os insetos apresentaram prolongamento do período de desenvolvimento e menor peso das lagartas aos 10 dias. A viabilidade da fase larval foi afetada pelas linhagens Mp705 e Mp706, enquanto que o peso de pupas foi menor na linhagem IAC103 BPl. A duração e viabilidade da fase pupal, a razão sexual e a \% de deformação de adultos foram menos importantes para a discriminação dos materiais. Os resultados demonstraram que os genótipos menos adequados para o desenvolvimento do inseto foram Mp707 e Zapalote Chico, seguidos de Mp706, Mp705 e Mp701, enquanto os mais adequados foram IAC103 N, IAC701 N e Mp496.

PALAVRAS-CHAVE: Insecta, lagarta-do-cartucho, resistência de plantas, Zea mays. 
Existe na literatura um considerável volume de informações sobre a resistência de milho à lagarta-do-cartucho, Spodoptera frugiperda (J.E.Smith). Os países que mais se destacam nesta área são os EUA, sobretudo os Estados do Mississippi e Geórgia e o México, onde diversos materiais têm sido identificados como portadores de genes para resistência a $S$. frugiperda e outras pragas, citados a seguir.

Wiseman et al. (1966) concluíram que genótipos derivados do Grupo 'Antigua 2D' são resistentes a $S$. frugiperda, o que foi confirmado, no Brasil, por Carvalho (1970). Durante a década de 1980 foram lançadas, nos EUA, diversas linhagens de milho resistentes a insetos: MpSWCB-4, resistente a Diatraea grandiosella (Dyar) (Scott \& Davis 1981a), Mp496, com resistência a $S$. frugiperda e Ostrinia nubilalis (Hübner) (Scott \& Davis 1981b) e Mp701 e Mp702 (Scott et al. 1982), Mp704 (Williams \& Davis 1982), Mp705, Mp706 e Mp707 (Williams \& Davis 1984) e Mp 708 (Williams et al. 1990) que são resistentes a $D$. grandiosella e $S$. frugiperda. Estes materiais foram testados em vários ensaios internacionais, em condições de campo, identificando-se sua capacidade de diminuir o peso e a viabilidade de lagartas de S. frugiperda, além de serem menos preferidos para oviposição e sofrerem menor dano foliar (Scott et al. 1977, Scott \& Davis 1981a, Williams \& Davis 1984, Ng et al. 1990, Videla et al. 1992).

Diversos materiais comerciais têm sido testados no Brasil (Lara et al. 1984, Melo \& Silva 1987, Marques et al. 1988, Vendramim \& Fancelli 1988), não tendo sido identificado nenhum material com resistência comprovada à lagarta-do-cartucho. Com relação às raças, Vendramim \& Fancelli (1988) verificaram que 'Zapalote Chico' e 'Cateto Palha Roxa' provocaram, em condições de laboratório, diminuição do peso e aumento da fase larval, demonstrando que estes materiais têm um certo grau de resistência à lagarta-docartucho. Wilson et al. (1991) concluíram que o genótipo Zapalote Chico sofre um dano foliar menor, além do que as lagartas nele desenvolvidas apresentam menor peso. Diversos acessos introduzidos do México têm se destacado como resistentes a $S$. frugiperda, e vem sendo utilizados como fontes de resistência em trabalhos de melhoramento (Viana 1994, Guimarães \& Viana 1994, Viana \& Silva 1994 e Viana \& Guimarães 1994). A Seção de Milho do Instituto Agronômico de Campinas (IAC) vem desenvolvendo linhagens de milho com genes para resistência a insetos mastigadores, denominados genes B e Pl. O gene Pl está relacionado com a produção de fitoalexinas pelas plantas (alcalóides, resinas, ácidos orgânicos e glucosídeos), e só se expressa quando ligado ao gene $\mathbf{B}$, dominante e complementar (Miranda \& Miranda 1993). Estes dois genes foram incorporados às linhagens suscetíveis IAC103 $\mathrm{N}$ e IAC701 N, formando as linhagens IAC103 BPl e IAC701 BPl, que podem apresentar algum nível de resistência às pragas mastigadoras da cultura do milho. O objetivo deste trabalho foi testar algumas linhagens de milho provenientes da Universidade do Mississippi (EUA) e alguns genótipos de milho provenientes do IAC, em relação à resistência a $S$. frugiperda.

\section{Material e Métodos}

Os ensaios foram desenvolvidos nos Laboratórios da Seção de Controle Biológico das Pragas da Estação Experimental do Instituto Biológico, Fazenda Mato Dentro, Campinas, com o objetivo de avaliar alguns aspectos biológicos de S. frugiperda nos seguintes genótipos de milho: Mp496, Mp701, Mp705, Mp706 e Mp707, linhagens obtidas e lançadas pela Universidade do Mississippi como resistentes a insetos mastigadores, especialmente $D$. grandiosella (Scott et al. 1982, Williams \& Davis 1982, 1984), O. nubilalis e S. frugiperda (Scott \& Davis 1981b, Scott et al. 1982, Williams \& Davis 1982, Williams \& Davis 1984); a raça centro-americana Zapalote Chico (ZC), resistente a $S$. frugiperda, as linhagens IAC103 BPl, IAC701 BPl, IAC701 N e IAC103 N e o híbrido simples IAC7777 
(IAC701 N x IAC103 N), da Seção de Milho do IAC.

Lagartas recém-eclodidas de $S$. frugiperda foram individualizadas em tubos de vidro $(2,5$ $\mathrm{x} 8,5 \mathrm{~cm}$ ) tampados com algodão hidrófugo e alimentadas com folhas dos diferentes genótipos. Coletou-se a primeira folha completamente desenvolvida do cartucho, aquela que terminou de se desenrolar, tornando visível a bainha, de plantas com 35 dias de idade. Foram utilizados 40 tubos (repetições) para cada genótipo; estes foram dispostos em prateleiras de madeira e mantidos em laboratório a $27 \pm 1^{\circ} \mathrm{C}, 70 \pm$ $10 \%$ de UR e fotofase de 14 horas. O alimento foi trocado diariamente. Após a formação, as pupas foram mantidas nos respectivos tubos até a emergência dos adultos, quando houve a sexagem. Foram avaliadas a duração e viabilidade das fases larval e pupal, peso das lagartas (com 10 dias de idade) e das pupas (24 horas após a formação), razão sexual e deformação dos adultos. Foram consideradas deformações os defeitos em asas, pernas, abdome ou tórax, bem como dificuldades na emergência, resultando em adultos presos às pupas. Foi realizada análise de variância para os parâmetros período e viabilidade da fase larval, peso larval após 10 dias de desenvolvimento, período e viabilidade da fase pupal, peso pupal 24 horas após a formação e \% de deformação de adultos. As comparações entre médias para as diversas variáveis foi feita através do teste de Tukey, a $5 \%$ de probabilidade.

\section{Resultados e Discussão}

Os resultados de peso das lagartas de $S$. frugiperda aos 10 dias de idade (Tabela 1 ) mostraram diferenças significativas entre os genótipos testados. Nos genótipos Mp707 e $\mathrm{ZC}$, observaram-se os menores pesos larvais, o que indica que em relação a esta variável, estes materiais apresentaram um certo nível de resistência. No grupo de genótipos mais adequados ao inseto (mais suscetíveis) em relação a esta variável, ficaram, em ordem crescente, 'IAC701 N', 'Mp496' e 'IAC103
N'. Pode-se observar que, para as linhagens IAC às quais incorporou-se o gene BPl (que está relacionado à produção de fitoalexinas), os pesos larvais foram significativamente menores em relação às respectivas linhagens sem este gene. Isto demonstra que, para o peso de lagartas 10 dias após a emergência a hipótese de que os genes $\mathbf{B}$ e $\mathbf{P l}$ conferem resistência a pragas do milho tem fundamento.

Os valores de duração da fase larval nos diferentes genótipos (Tabela 1) demonstraram diferenças menos evidentes do que para os pesos larvais. Nas linhagens Mp707 e ZC, verificaram-se os maiores períodos, respectivamente 17,5 e 17,2 dias, enquanto que em 'IAC701 N' e 'IAC103 N' registraram-se os menores períodos larvais. Levando-se em consideração que o alongamento da fase larval é indicativo de menor adequação do substrato alimentar e, conseqüentemente, da presença de algum nível de resistência, pode-se concluir que 'Mp707' e 'ZC' foram, sob este aspecto, os genótipos mais resistentes e 'IAC701 N' e 'IAC103 N', os mais suscetíveis a $S$. frugiperda. Apesar das diferenças estatísticas terem sido menos evidentes, observa-se uma relação inversa entre período e peso larval, pois os menores períodos larvais corresponderam a genótipos onde se obtiveram os maiores pesos larvais.

A viabilidade larval nos diferentes genótipos (Tabela 1) foi variável. Diferenças significativas foram registradas entre o valor observado na linhagem Mp706 (56,5\%) e aqueles obtidos em 'Mp496', 'IAC7777' e 'IAC701 N', que variaram entre 90,0 e 95,1\%, indicando que, sob este aspecto, 'Mp706' foi o material menos adequado ao desenvolvimento do inseto. A observação das mortalidades larvais acumuladas (Fig. 1) evidencia que os genes $\mathbf{B}$ e $\mathbf{P l}$ da linhagem IAC701 BPl aumentaram a mortalidade larval se comparado à linhagem IAC701 N; a partir do $10^{\circ}$ dia de desenvolvimento a mortalidade na linhagem BPI manteve-se quatro vezes superior à observada em 'IAC701 N'. Isto demonstra que a hipótese de resistência destes genes tem fundamento 
Tabela 1. Peso (aos 10 dias de idade), duração e viabilidade de lagartas de Spodoptera frugiperda alimentadas com folhas de diferentes genótipos de milho.

\begin{tabular}{llcc}
\hline Genótipo & $\begin{array}{c}\text { Peso }(\mathrm{mg}) \\
(\mathrm{X} \pm \mathrm{EP})\end{array}$ & $\begin{array}{c}\text { Duração (dias) } \\
(\mathrm{X} \pm \mathrm{EP})\end{array}$ & $\begin{array}{c}\text { Viabilidade (\%) } \\
(\mathrm{X} \pm \mathrm{EP})\end{array}$ \\
\hline IAC103 N & $376,5 \pm 8,0 \mathrm{a}^{1}$ & $14,0 \pm 1,0 \mathrm{e}^{1}$ & $83,5 \pm 2,5 \mathrm{ab}^{1}$ \\
Mp496 & $351,2 \pm 10,3 \mathrm{a}$ & $15,2 \pm 0,9 \mathrm{cde}$ & $90,0 \pm 2,6 \mathrm{a}$ \\
IAC701 N & $347,7 \pm 9,9 \mathrm{a}$ & $14,7 \pm 1,5 \mathrm{de}$ & $95,1 \pm 4,2 \mathrm{a}$ \\
IAC701 BP1 & $237,9 \pm 10,3 \mathrm{~b}$ & $16,0 \pm 1,5 \mathrm{bcd}$ & $77,8 \pm 4,0 \mathrm{ab}$ \\
IAC103 BP1 & $188,5 \pm 8,5 \mathrm{bc}$ & $15,1 \pm 1,3 \mathrm{cde}$ & $82,5 \pm 3,3 \mathrm{ab}$ \\
IAC7777 & $180,3 \pm 8,2 \mathrm{bc}$ & $15,3 \pm 1,2 \mathrm{cde}$ & $92,9 \pm 3,2 \mathrm{a}$ \\
Mp705 & $176,4 \pm 8,3 \mathrm{bcd}$ & $16,1 \pm 1,2 \mathrm{abc}$ & $65,0 \pm 4,5 \mathrm{ab}$ \\
Mp706 & $168,3 \pm 8,4 \mathrm{~cd}$ & $16,4 \pm 1,4 \mathrm{abc}$ & $56,5 \pm 4,4 \mathrm{~b}$ \\
Mp701 & $163,9 \pm 8,9 \mathrm{~cd}$ & $16,9 \pm 1,3 \mathrm{ab}$ & $82,5 \pm 3,6 \mathrm{ab}$ \\
ZC & $109,6 \pm 7,0 \mathrm{de}$ & $17,2 \pm 1,3 \mathrm{ab}$ & $84,8 \pm 2,8 \mathrm{ab}$ \\
Mp707 & $89,7 \pm 7,1 \mathrm{e}$ & $17,5 \pm 1,2 \mathrm{a}$ & $87,2 \pm 3,0 \mathrm{ab}$ \\
\hline Média & 206,6 & 15,8 & 81,6 \\
C.V.(\%) & 36,8 & 10,6 & 16,3 \\
F & $47,35 *$ & $13,03 *$ & $3,05 *$ \\
\hline
\end{tabular}

${ }^{1}$ Médias seguidas de mesma letra não diferem significativamente entre si, pelo teste de Tukey, ao nível de $5 \%$ de probabilidade.

também quanto aos efeitos sobre a mortalidade larval. Com relação à viabilidade larval nas linhagens Mp (Tabela 1), constatouse que 'Mp707', apesar de ter promovido o menor peso larval, ocasionou alta viabilidade, se comparada a 'Mp706' e 'Mp705'. Estas últimas linhagens provocaram as menores viabilidades larvais, porém não afetaram, em igual intensidade, o peso das lagartas aos 10 dias de idade. Observando-se os dados de literatura, verifica-se que nem sempre a viabilidade larval é afetada sensivelmente pelos genótipos resistentes; Melo \& Silva (1987) encontraram pequenas variações entre os genótipos brasileiros por eles testados e Vendramim \& Fancelli (1988) obtiveram alta viabilidade $(98,0 \%)$ das larvas em ' $\mathrm{ZC}$ ' (um dos menos adaptados ao desenvolvimento do inseto, no referido trabalho).

Os pesos pupais de $S$. frugiperda (Tabela 2) apresentaram variações menores que as observadas para peso larval. A linhagem IAC103 BPl foi a que mais afetou o peso pu- pal, sendo significativamente diferente de IAC103 N. Nota-se nesta linhagem um efeito dos genes BPl, pois os pesos pupais para as linhagens com e sem o gene foram diferentes e situaram-se nos extremos opostos, confirmando a resistência. Para o caso de 'IAC701 N' e 'IAC701 BPl', isto não ocorreu. Tomando como base este variável, pode-se considerar que o genótipo IAC103 $\mathrm{BPl}$ foi o menos adequado à espécie, uma vez que apresentou o menor peso pupal. Em contrapartida, 'IAC103 N', com o maior valor para esta variável, foi o mais adequado.

Observou-se que os pesos pupais não refletiram os padrões de desenvolvimento apresentados pelas lagartas, já que em diversos genótipos onde as lagartas tiveram pesos baixos aos 10 dias, formaram-se pupas com peso igual ou maior que aquelas provenientes de materiais que proporcionaram pesos larvais elevados (Fig. 2). Isto ocorreu para a maioria dos genótipos (Mp705, Mp706, Mp707, Mp701, ZC, IAC7777, 

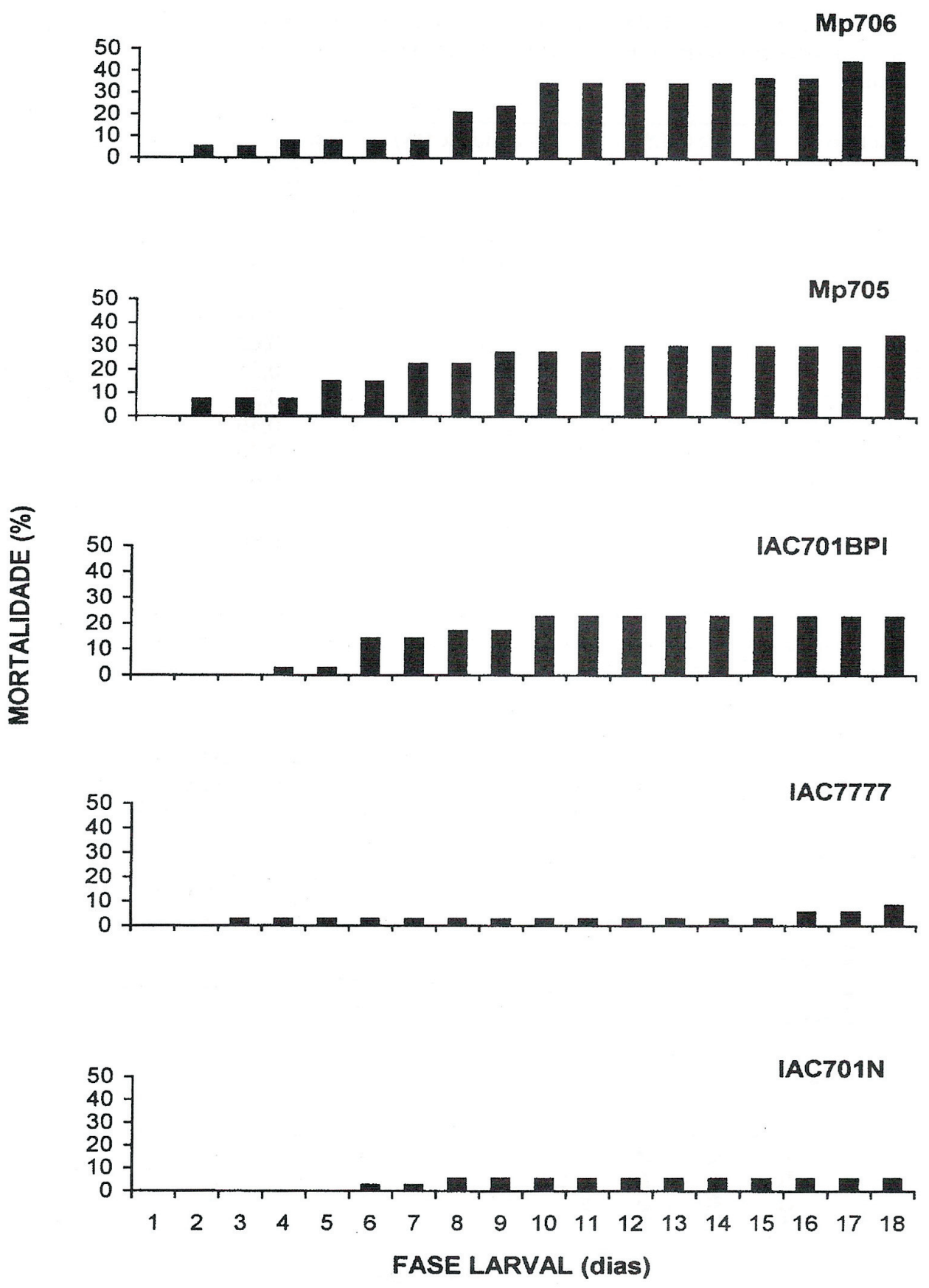

Figura 1. Mortalidade acumulada de Spodoptera frugiperda alimentada com folhas de diferentes genótipos de milho. 
Tabela 2. Peso e viabilidade da fase pupal, razão sexual e deformação de adultos (\%) de Spodoptera frugiperda provenientes de lagartas alimentadas com folhas de diferentes genótipos de milho.

\begin{tabular}{llccr}
\hline Genótipo & $\begin{array}{c}\text { Peso }(\mathrm{mg}) \\
(\mathrm{X} \pm \mathrm{EP})\end{array}$ & $\begin{array}{c}\text { Viabilidade }(\%) \\
(\mathrm{X} \pm \mathrm{EP})\end{array}$ & $\begin{array}{c}\text { Razão Sexual } \\
(\mathrm{X} \pm \mathrm{EP})\end{array}$ & $\begin{array}{r}\text { \% Deformação } \\
(\mathrm{X} \pm \mathrm{EP})\end{array}$ \\
\hline IAC103 N & $239,2 \pm 4,2 \mathrm{a}^{1}$ & $91,3 \pm 2,8$ & 0,51 & $10,3 \pm 3,4$ \\
Mp705 & $225,6 \pm 4,9 \mathrm{ab}$ & $97,1 \pm 2,2$ & 0,56 & $13,4 \pm 3,5$ \\
Mp496 & $219,4 \pm 5,0 \mathrm{abc}$ & $97,2 \pm 2,1$ & 0,44 & $6,2 \pm 2,5$ \\
Mp707 & $217,0 \pm 5,1 \mathrm{abc}$ & $93,6 \pm 2,5$ & 0,40 & $12,9 \pm 1,5$ \\
Mp701 & $212,3 \pm 5,9 \mathrm{bc}$ & $89,1 \pm 2,4$ & 0,62 & $18,4 \pm 2,3$ \\
Mp706 & $212,0 \pm 4,9 \mathrm{bc}$ & $100,0 \pm 0,0$ & 0,35 & $24,6 \pm 1,7$ \\
IAC701 N & $211,5 \pm 5,1 \mathrm{bc}$ & $94,4 \pm 0,0$ & 0,38 & $9,5 \pm 4,1$ \\
ZC & $210,0 \pm 5,7 \mathrm{bc}$ & $93,3 \pm 2,5$ & 0,46 & $11,1 \pm 3,7$ \\
IAC7777 & $206,9 \pm 5,4 \mathrm{bc}$ & $91,4 \pm 2,9$ & 0,50 & $13,5 \pm 3,9$ \\
IAC701 BP1 & $204,1 \pm 5,7 \mathrm{bc}$ & $100,0 \pm 0,0$ & 0,62 & $30,6 \pm 3,8$ \\
IAC103 BP1 & $196,8 \pm 5,2 \mathrm{c}$ & $93,7 \pm 2,48$ & 0,68 & $10,7 \pm 3,4$ \\
\hline Média & 213,6 & 94,7 & 0,50 & 14,7 \\
C.V(\%) & 13,2 & 8,6 & - & 84,6 \\
F & $4,23 *$ & 0,76 n.s. & - & 1,34 n.s. \\
\hline
\end{tabular}

${ }^{1}$ Médias seguidas de mesma letra não diferem significativamente entre si, pelo teste de Tukey, ao nível de $5 \%$ de probabilidade.

IAC701 BPl e IAC103 BPl). Consideran do-se os dados de pesos larvais, esperava-se que nas linhagens Mp ocorressem pupas menores do que nos demais materiais citados, e não o inverso. Este tipo de ação "compensatória" dos insetos pode ser em parte explicado

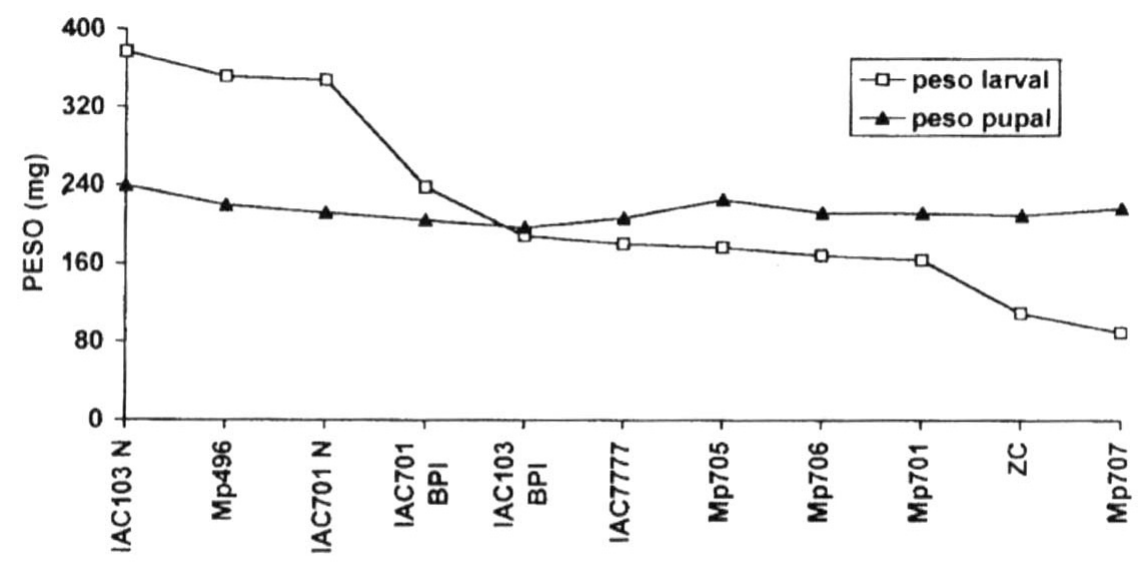

\section{GENÓTIPOS}

Figura 2. Peso de lagartas (10 dias de idade) e de pupas (24 horas) de Spodoptera frugiperda desenvolvidas em folhas de diferentes genótipos de milho. 
porque as lagartas que tiveram menores pesos larvais apresentaram também períodos larvais prolongados, significando que tiveram também um maior tempo de alimentação, recuperando-se e formando pupas comparáveis aos tratamentos onde os períodos larvais foram menores. $\mathrm{Na}$ literatura encontram-se alguns casos semelhantes (Wiseman \& Widstrom 1986, Melo \& Silva 1987, Vendramim \& Fancelli 1988).

Os valores registrados para as viabilidades pupais nos 11 genótipos testados (Tabela 2) demonstraram que esta variável não foi afetada significativamente pelos materiais utilizados. De modo geral, a viabilidade foi alta (94,7\%, média dos 11 genótipos), com variações de 89,1 a 100,0\%.

A razão sexual (total de fêmeas dividido pelo total de indivíduos) de $S$. frugiperda apresentou variações com relação aos genótipos onde os insetos foram criados (Tabela 2). A menor razão sexual foi verificada em 'Mp706' $(0,35)$ e a maior $(0,68)$ foi observada em 'IAC103 BPl'. A média geral registrada foi 0,50 . Não existiu relação entre a razão sexual e os dados de pesos de lagartas, período e viabilidade larval e pupal e peso de pupas. Tanto materiais com altos pesos e curtos períodos larvais quanto o inverso apresentaram razões sexuais acima ou abaixo da média $(0,5)$, sem qualquer relação aparente. $\mathrm{O}$ mesmo foi observado para as viabilidades larvais e pupais.

Os dados de percentagem de deformação de adultos de $S$. frugiperda (Tabela 2), demonstraram que, apesar de terem sido observadas diferenças de até $25,0 \%$ entre tratamentos ('IAC701 BPl' contra 'Mp496'), não houve diferença significativa entre os genótipos. Verifica-se que a fase larval foi mais afetada que a fase pupal, o que significa que as variáveis referentes àquela fase devem ser consideradas como mais adequadas para a discriminação dos materiais através de testes de biologia.

Uma análise global dos resultados indica que os genótipos mais resistentes a $S$. frugiperda foram Mp707 e ZC, vindo em seguida os genótipos Mp706, Mp705 e
Mp701. Os materiais mais suscetíveis foram IAC103 N, IAC701 N e Mp496. Os genes B e Pl incorporados às linhagens do híbrido simples IAC 7777 conferiram uma resistência moderada a $S$. frugiperda.

\section{Agradecimentos}

Ao Dr. Frank Davis, Mississippi State University pelo fornecimento das sementes das linhagens Mp. Ao Dr. Luiz Miranda, Seção de Milho do Instituto Agronômico de Campinas, pelo fornecimento das linhagens com e sem o gene B e Pl. Ao Dr. Antonio Batista, Instituto Biológico, pela cessão dos laboratórios para os testes.

\section{Literatura Citada}

Carvalho, R.P.L. 1970. Danos, flutuação da população, controle e comportamento de Spodoptera frugiperda (J.E. Smith, 1797) e suscetibilidade de diferentes genótipos de milho, em condições de campo. Tese de doutorado, ESALQ/USP, Piracicaba, $170 \mathrm{p}$.

Guimarães, P.E.O. \& P.A. Viana. 1994. Sintético CMS 23 para resistência a Spodoptera frugiperda. Rel. Téc. Anual Cent.Nac. Pesq. Milho e Sorgo 1992/93: 136.

Lara, F.M., J. Ayala Osuña, O. Abdelnur Júnior. 1984. Comportamento de genótipos de milho em relação ao ataque de Spodoptera frugiperda (J.E. Smith, 1797) e Heliothis zea (Bod., 1850). Científica 12: 77-83.

Marques, C.A.S, O.B. de Camargo, J.A. Osuña. 1988. Avaliação fenotípica de populações de milho, sob condições de seca para os danos de Heliothis zea e Spodoptera frugiperda, e outras características agronômicas. In Anais Congresso Nacional de Milho e Sorgo, 16, Belo Horizonte, p. 327-336. 
Melo, M. \& R.F.P. da Silva. 1987. Influência de três cultivares de milho no desenvolvimento de Spodoptera frugiperda (J.E. Smith, 1797) (Lepidoptera: Noctuidae). An. Soc. Entomol. Brasil 16: 37-49.

Miranda, L.T. de \& L.E.C. de Miranda. 1993. Genética ecológica. p. 363-409. In A.M.C. Furlani \& G.P. Viégas, O Melhoramento de Plantas no Instituto Agronômico, Campinas, Fundação IAC, $524 \mathrm{p}$.

Ng, S.S., F.M. Davis., W.P. Williams. 1990. Ovipositional response of southwestern corn borer (Lepidoptera: Pyralidae) and fall armyworm (Lepidoptera:Noctuidae) to select maize hybrids. J. Econ. Entomol. 83: 1575-7.

Scott, G.E. \& F.M. Davis. 1981a. Registration of MpSWCB-4 population of maize. Crop Sci. 21: 148.

Scott, G.E. \& F.M. Davis. 1981 b. Registration of Mp496 inbreed line of maize. Crop Sci. 21: 353.

Scott, G.E., F.M. Davis, G.L. Beland, F.M. Williams, S.B. King. 1977. Host plant resistance is necessary for late planted corn. Mississippi Agricultural \& Forestry Exp. St., Res. Rep., vol. 3, nº 13, 4 p.

Scott, G.E., F.M. Davis, W.P. Williams. 1982. Registration of Mp701 and Mp702 germplasm lines of maize. Crop Sci. 22: 1270 .

Vendramim, J.D. \& M. Fancelli. 1988. Efeito de genótipos de milho na biologia de Spodoptera frugiperda (J.E. Smith, 1797) (Lepidoptera:Noctuidae). An. Soc. Entomol. Brasil 17: 141-50.

Viana, P.A. 1994. Avaliação de genótipos de milho para resistência à lagarta-docartucho, Spodoptera frugiperda. Rel. Téc. Anual Cent. Nac. Pesq. Milho e Sorgo, 1992/93: 136.

Viana, P.A. \& P.E.O. Guimarães. 1994. Melhoramento da população MIRT de milho para resistência à lagarta-docartucho, Spodoptera frugiperda. Rel. Téc. Anual Cent. Nac. Pesq. Milho e Sorgo 1992/93: 138-9.

Viana, P.A. \& A.E. Silva. 1994. Melhoramento da população de milho CMS 14 C para resistência à lagarta-docartucho, Spodoptera frugiperda. Rel. Téc. Anual Cent. Nac. Pesq. Milho e Sorgo 1992/93: 138

Videla, G.W., F.M. Davis, W.P. Williams, S.S. NG. 1992. Fall armyworm (Lepidoptera: Noctuidae) larval growth and survivorship on susceptible and resistant corn at different vegetative growth stages. J. Econ. Entomol. 85: 2486-91.

Williams, W.P. \& F.M. Davis. 1982. Registration of Mp704 germplasm line of maize. Crop Sci. 22: 1269.

Williams, W.P. \& F.M. Davis. 1984. Registration of Mp705, Mp706 and Mp707 germplasm lines of maize. Crop Sci. 24: 1217.

Williams, W.P., F.M. Davis, G.L. Windham. 1990. Registration of Mp 708 germplasm line of maize. Crop Sci. 30:757.

Wiseman, B.R., Painter, R.H., Wasson, C.E. 1966. Detecting corn seedlings differences by visual classification of damage by the fall armyworm. J. Econ. Entomol. 59: 1211-4.

Wiseman, B.R. \& N.W. Widstron. 1986. Mechanisms of resistance in "Zapalote Chico" corn silks to fall armyworm (Lepidoptera: Noctuidae) larvae. J. Econ. Entomol. 79: 1390-3.

Wilson, R.L., B.R. Wiseman, G.L. Reed. 1991. Evaluation of J. C. Eldredge popcorn collection for resistance to corn earworm, fall armyworm (Lepdoptera:Noctuidade) and european corn borer. J. Econ. Entomol. 84:693-8.

Recebido em 24/11/96. Aceito em 09/07/97. 